\title{
Three- Dimensional Simulation of Crack Propagation using Finite Element Method
}

\author{
Abdulnaser M. Alshoaibi, Abdulrahman A. Bin Ghouth, Yahya Ali Fageehi
}

\begin{abstract}
The 3D finite element software ANSYS Workbench software has been employed for simulation of engineering geometries which are containing a pre-cracks and holes. The new feature in this software is using the smart crack growth procedure and the mesh smoothing technique which provides an adaptive and smooth mesh around the crack path as well as the higher stresses area. Under the assumption of LEFM, the stress intensity factors was used as a crack growth criterion which provided as indicators of failure compared to the fracture toughness or threshold stress intensity factors (SIFs) in both static and dynamic loading respectively. The stress intensity factors were calculated for every crack growth step and the fatigue life time was predicted according to the number of cycles. The effect of the nominal notch position of the crack was illustrated. Simulations performed with Ansys show an identical crack path on structures that is in line with that of the experimental and numerical results performed by other researchers.
\end{abstract}

Keywords: Fatigue analysis, FEM, ANSYS Workbench, Crack growth path, Nominal notch position

\section{INTRODUCTION}

Over the past few decades, disasters caused by fracture failures in various structures caused numerous deaths, injuries and economic losses. In 1978, the estimated annual cost of these failures in the USA was $\$ 119$ million dollars. This led the engineers to develop numerical methods to prevent these failures which in turn would also reduce the finical loses by $\$ 63$ billion dollars [1]. In today's century, crack modelling on structures has become a fundamental topic in the analysis of fracture mechanics. This has become an important step due to the failures in automobiles, aircraft, marine, structural buildings, just to name a few. These failures have caused many losses of life, injuries, damage to the environment, and economic losses. One of the most popular methods used for the crack propagation analysis is the finite element. This method is used for predicting crack trajectories, stress intensity factors at different crack lengths, and other fracture mechanics parameters that occur on structures.

Revised Manuscript Received on December 30, 2019.

* Correspondence Author

Abdulnaser M. Alshoaibi*, Mechanical Engineering Department, Jazan University, P. O. Box 706, Jazan 45142, Kingdom of Saudi Arabia. Email: alshoaibi@gmail.com

Abdulrahman Bin Ghouth, Mechanical Engineering Department, Jazan University, KSA,Email: abduadel2016@gmail.com

Yahya Ali Fageehi, Mechanical Engineering Department, Jazan University, KSA,Email: y.fageehi@gmail.com

(C) The Authors. Published by Blue Eyes Intelligence Engineering and Sciences Publication (BEIESP). This is an open access article under the CC BY-NC-ND license (http://creativecommons.org/licenses/by-nc-nd/4.0/)
The stress intensity factors is an important parameter in the crack growth analysis which used as criteria for crack initiation and propagation. Numerous handbooks of stress intensity factors calculation are available ([2], [3]) for specific geometries and loading. Due to the limitation of the analytical solution of stress intensity factors, as well as the experimental cost is high, the numerical analysis is the best alternative if the precision of the computational software is achieved [4]. Stress intensity factors can be computed by various methods like the boundary element and finite element methods [5]. There exist two categories of commercial FEM programs, finite element programs such as ANSYS, ABAQUS, NASTRAN, etc. can be used to add elements manually and perform analysis on complex structures. The other type is professional FEM programs, such as NASGROW, AF-GROSS, etc. these are more expensive but provide a high precision calculation [6]. However, there are limitations when it comes to more complicated geometries and loading conditions. This is due to the density of the generated mesh as well as the element type used. Other researchers developed their own two-dimensional source code program to simulate fatigue analysis and crack growth in both quasi-static and cyclic loading as well as the prediction of stress intensity factors using adaptive mesh strategy [7-11]. There are many existing analytical equations for the stress intensity factors in the literature [12], [2], [13]. These equations are only limited for standard geometries under specified loading. For nonstandard geometries, the numerical methods like finite element was used for the prediction of SIFs [14]. The objectives of this paper are using the ANSYS workbench software for the simulation of crack growth path and show the effect of the nominal notch position on the crack trajectory.

\section{ANSYS MECHANICAL}

ANSYS workbench is a computational software for simulation of engineering structures using finite element method. the new version of ANSYS 19.2 implements a new feature known as SMART CRACK GROWTH, for the analysis of the stress intensity factor, crack propagation, number of cycles, etc $[15,16]$. The fatigue analysis was performed using the Paris' law equation under constant amplitude loading. Based on the Paris' Law [17], the fatigue life time is predicted according as:

$$
\frac{d a}{d N}=C \Delta K^{m}
$$

where $\mathrm{da} / \mathrm{dN}$ is crack propagation rate as a function of the number of cycles, $\mathrm{C}$ and $\mathrm{m}$ are experimental testing constant for materials and $\Delta \mathrm{K}$ is the range of SIFs through a life cycle.

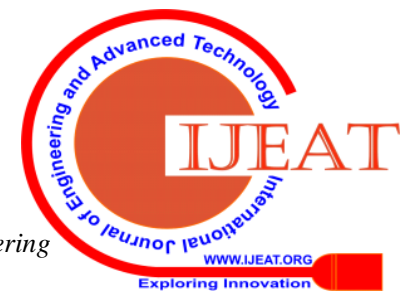




\section{NUMERICAL RESULTS AND DISCUSSION}

In this section, the simulations performed by using Ansys Workbench were compared to the experimental and numerical results performed by other researchers for three different geometries of the modified compact tension specimens with five holes.

\section{3-1 Modified Compact Tension Specimens with five holes}

The dimensions for this geometry is shown in Figure 1 with different notch tip position as shown in Table 1 . These different in the notch tip position produced three different curvilinear crack growth configuration as well as the stress intensity factors also affected by these configuration. Furthermore, the contour stress distribution like Von-Misses stress, maximum principal stress, minimum principle stress and shear stress will be different in each case.

The material for this geometry is nickel-based superalloy rolled sheet which has the Young's modulus $E=211 \mathrm{GPa}$, the Poisson's ratio $(v=0.3)$ yield stress $=422 \mathrm{GPa}$ and ultimate stress $=838 \mathrm{GPa})$. The applied load is a point load of $3.6 \mathrm{KN}$ with a load ratio $R=0.1$.

Table.1 Nominal notch tip positions

\begin{tabular}{|c|c|c|c|}
\hline Specimen Number & \multicolumn{3}{c|}{ Nominal Notch Tip (mm) } \\
\hline & $(\mathrm{H})$ & $(\mathrm{x})$ & $(\mathrm{y})$ \\
\hline Case 1 & 22.4 & -32 & 25.6 \\
\hline Case 2 & 25.6 & -32 & 22.4 \\
\hline Case 3 & 23.2 & -32 & 24.8 \\
\hline
\end{tabular}
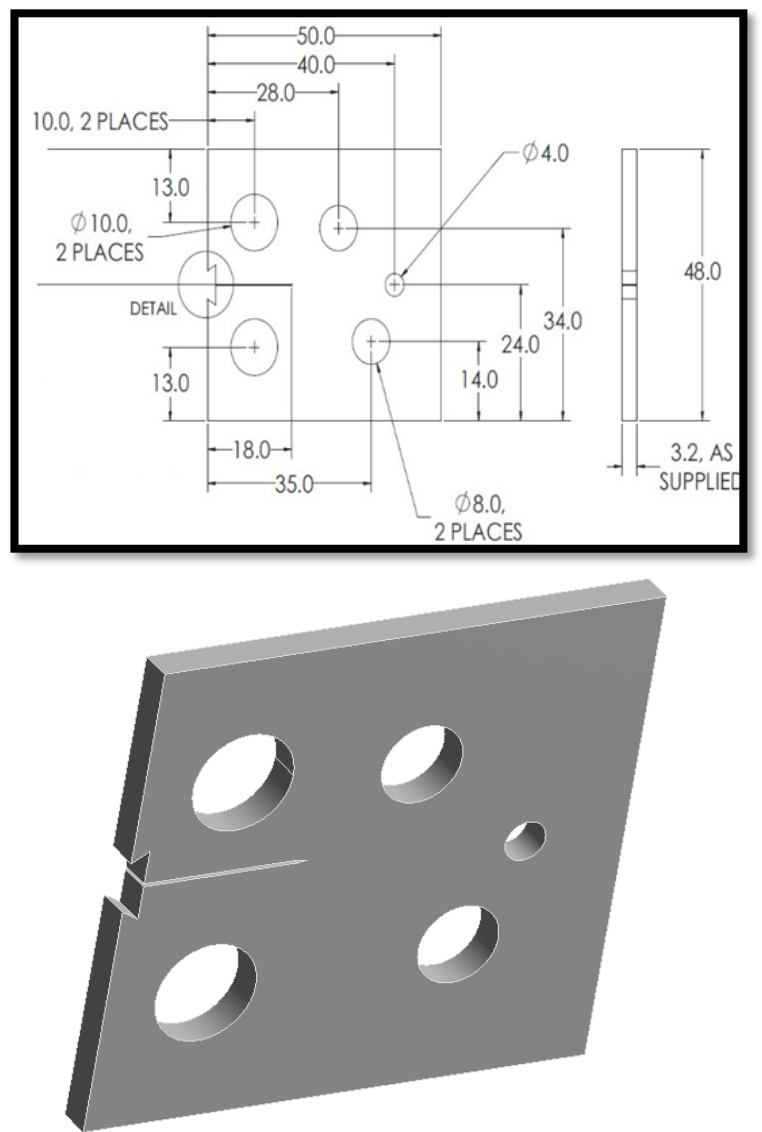

Fig.1: Geometric dimension of the specimen (all dimensions are in $\mathbf{m m}$ ) (a) 2D (b) $3 D$
Based on the nominal notch positions there are three different cases which are:

\section{Case 1}

In this case the position of crack with height of $\mathrm{H}=22.4 \mathrm{~mm}$. the geometry and the initial mesh is shown in Figure 2. The number of nodes are 18363 as well as the number of elements are 11064.

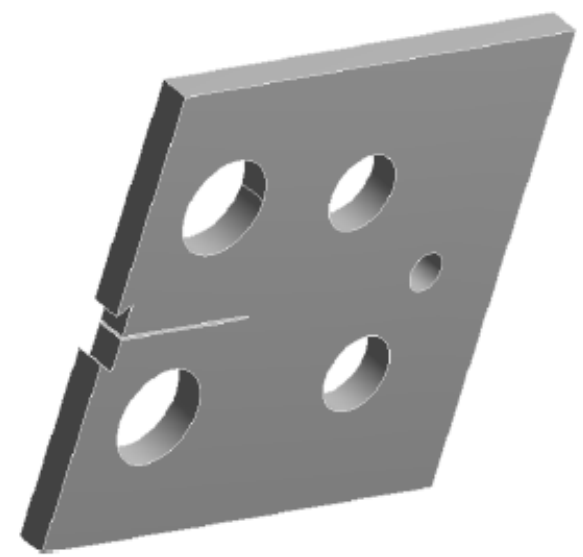

(a)

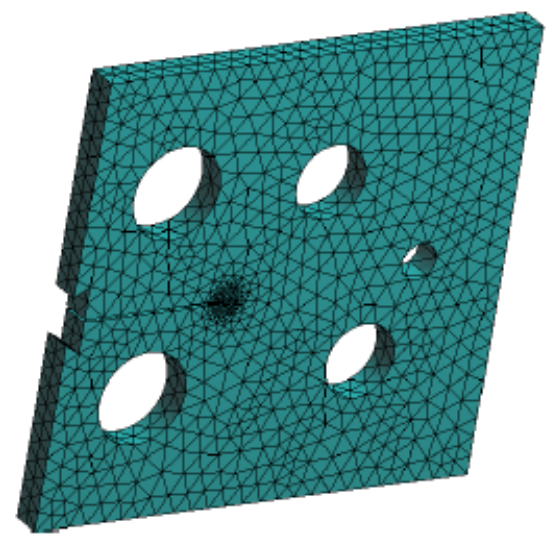

(b)

Fig.2: Case 1 (a) geometry (b) initial mesh

Figure 3 shows the simulated crack growth path predicted by using Ansys compared to the experimental (Figure 3b) and numerical crack growth path (Figure 3c) obtained by [18] and [19] which almost identical. Wagner [18 and 19] used a hypercomplex finite element method (ZFEM) to predict the crack path through a two-dimensional quasi-static model of a linear-elastic isotropic homogeneous solid object after extending the real-valued nodal coordinates of a finite element model into a high-order hypercomplex domain. Wagner [18] also compared his numerical results for crack path produced by FRANC3D as shown in Figure 3(c). Obviously, the curvature crack grow toward the hole based on it nominal position and sink in the hole. 


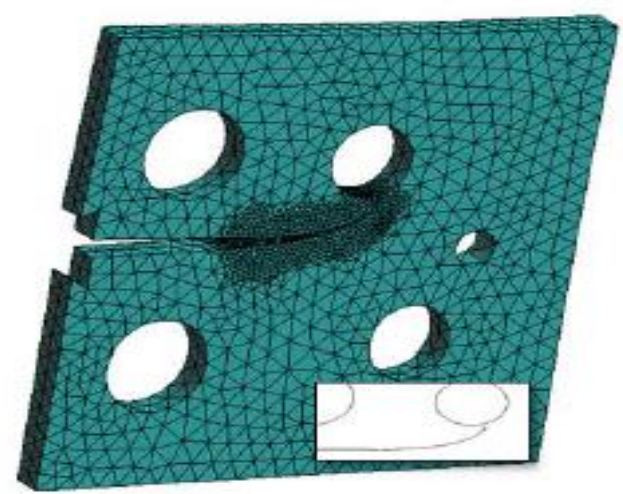

(a)

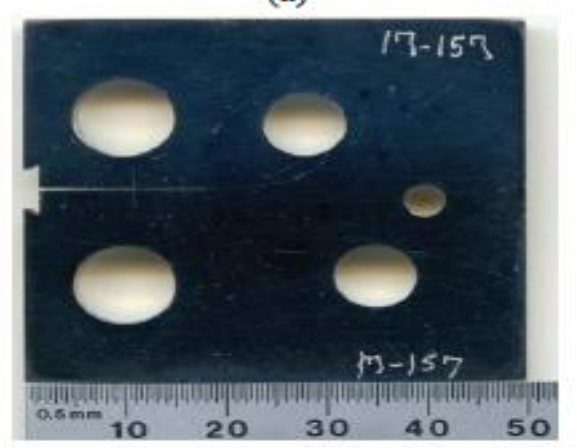

(b)

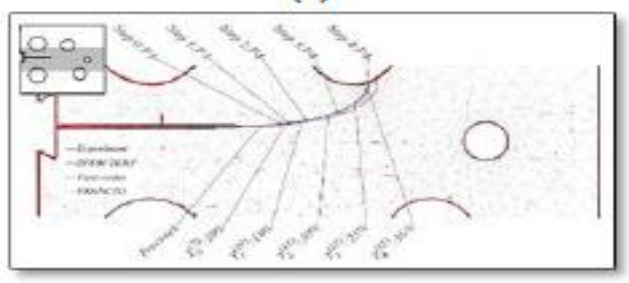

(c)

Fig.3: Case 1, crack path by a) ANSYS b) Experimental crack bath obtained by [18] and [19] c) Numerical crack path obtained by [19]

\section{Case 2}

In this case, the nominal crack tip position is $\mathrm{H}=25.6 \mathrm{~mm}$. the geometry and the initial mesh is shown in Figure 4. The number of nodes are 18430 as well as the number of elements are 11093.

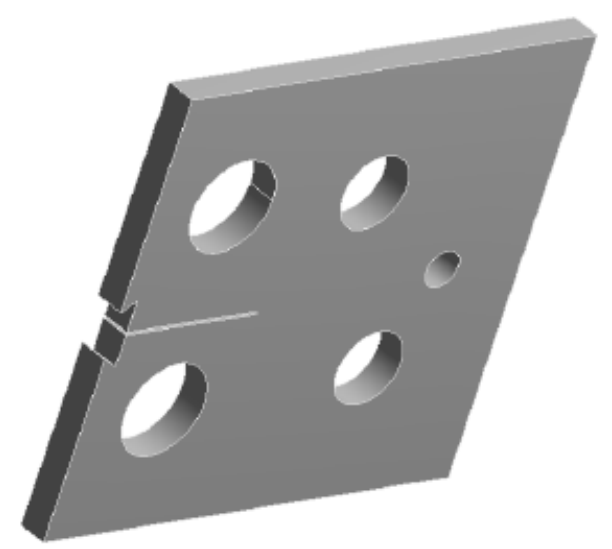

(a)

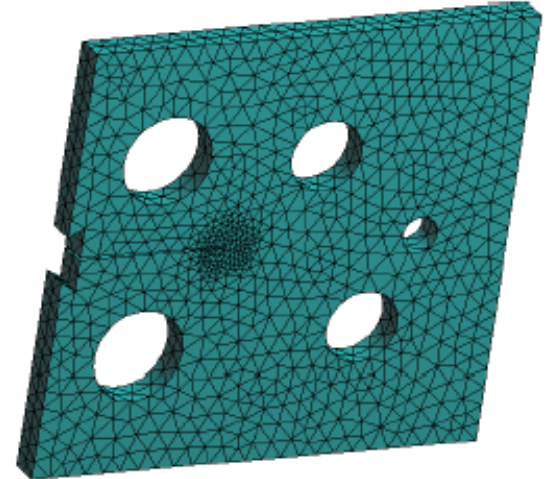

(b)

Fig. 4: Case 2 geometry and initial mesh

The difference on the nominal crack tip position between this case and the previous case was only $3.1 \mathrm{~mm}$ but the crack growth path is totally different and goes toward another hole as shown in Figure 6. The simulated curvature crack path is also compared to the experimental and numerical study performed by [18] and [19]. The simulated crack path is almost identical to the experimental and numerical paths even also with the FRANC3D simulation program results as shown in Figure 5c.

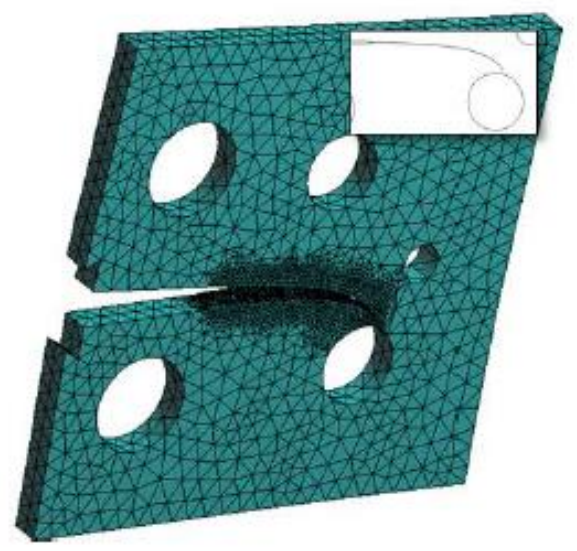

(a)

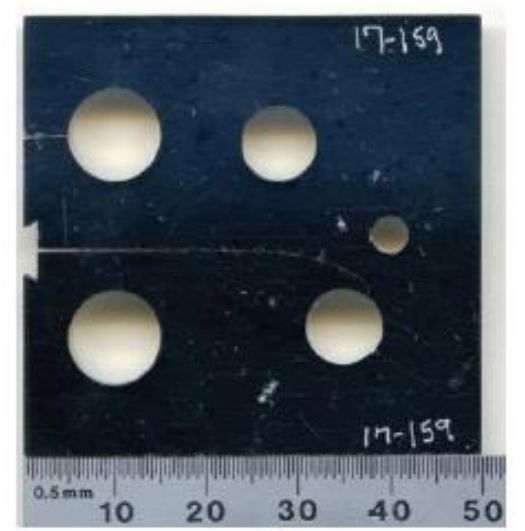

(b) 


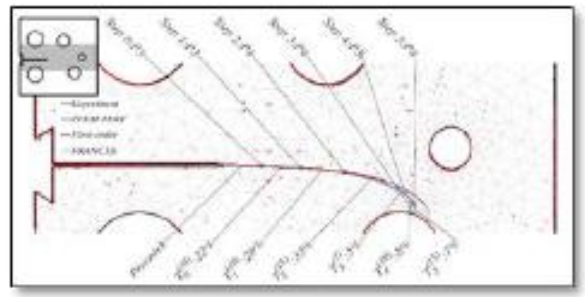

(c)

Fig.5: Case 2, crack path by a) ANSYS b) Experimental crack bath obtained by [18] and [19] c) Numerical crack path obtained by [19]

\section{Case 3}

In this case, the nominal crack tip position is $\mathrm{H}=23.2 \mathrm{~mm}$. The geometry and the initial mesh is shown in Figure 6. The number of nodes are 19620 as well as the number of elements are 11283.

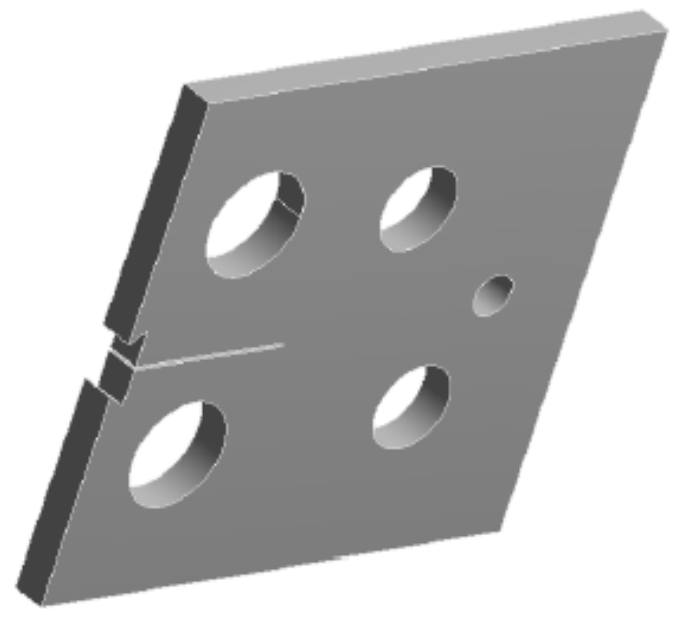

(a)

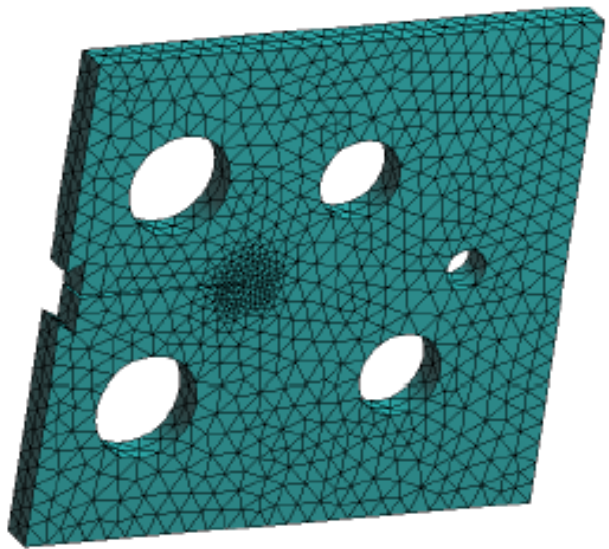

(b)

Fig. 6: Case 3 (a) geometry (b) initial mesh

In this case the nominal notch position in between both cases one and two which shows different crack path even though the different in nominal notch position is not much. As seen in Figure 7, the agreement between the predicted crack path using Ansys and the experimental study performed by [18] is very good. Furthermore, the predicted crack path by in the present study is more accurate than that of the simulation results obtained by [18] as shown in Figure 7c.

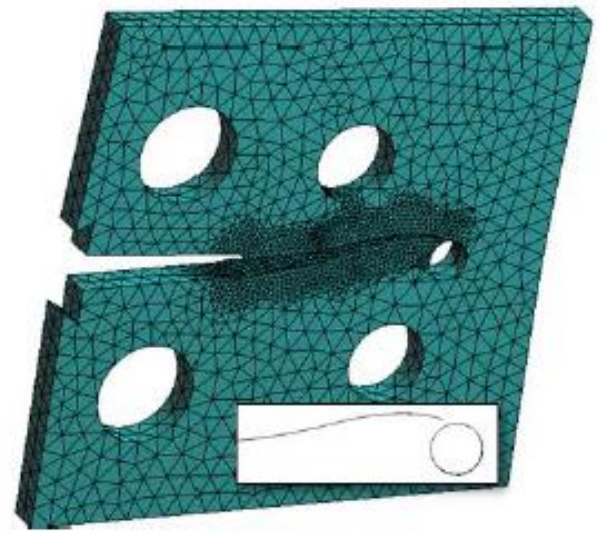

(a)

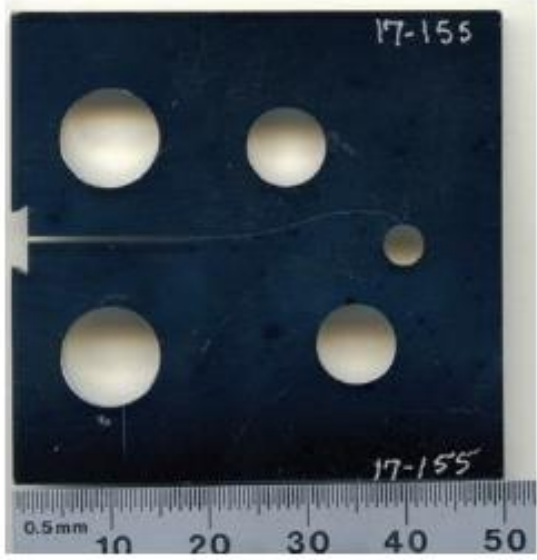

(b)

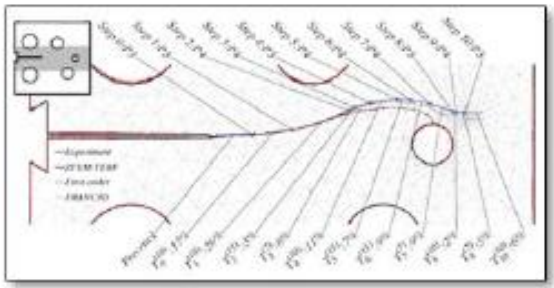

(c)

Fig.7: Case 3, crack path by a) ANSYS b) Experimental crack bath obtained by [18] and [19] c) Numerical crack path obtained by [19]

Figure 8 shows the first mode of stress intensity factors $\left(\mathrm{K}_{\mathrm{I}}\right)$ in the three cases versus the crack length. As shown in this figure, the influence of the upper hole in increasing the values of the stress intensity factor is clear. For the same reason due to the effect of the lower hole which effect the crack path direction to growth toward it, the values of $\mathrm{K}_{\mathrm{I}}$ is also higher than that of case three. In case three, the influence of the last small hole is lower compared to the upper and lower holes in the previous holes, so that the $\mathrm{K}_{\mathrm{I}}$ is the lowest.

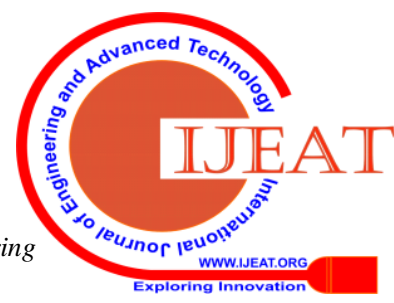




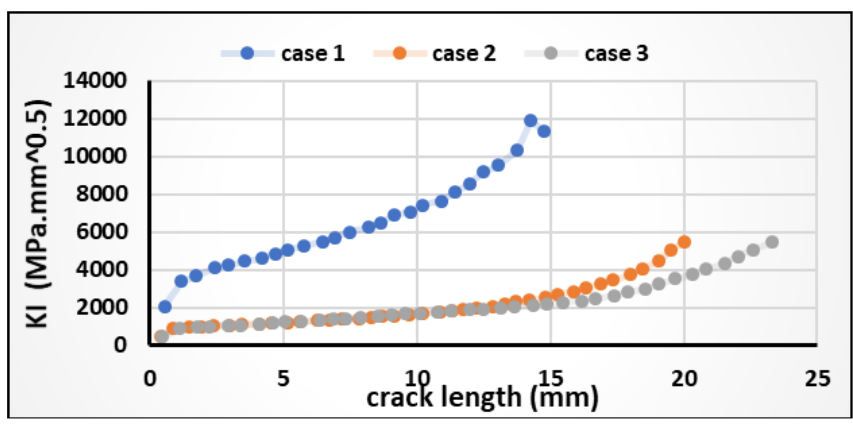

Fig. 8: Mode I stress intensity factor for the three cases

Figure 9 shows the values of mode II of stress intensity factors $\left(\mathrm{K}_{\mathrm{II}}\right)$. As seen in this figure there is a higher values of $\mathrm{K}_{\mathrm{II}}$ in case one only where as a very small values in both case two and three due to the different in the straight and curvature crack paths.

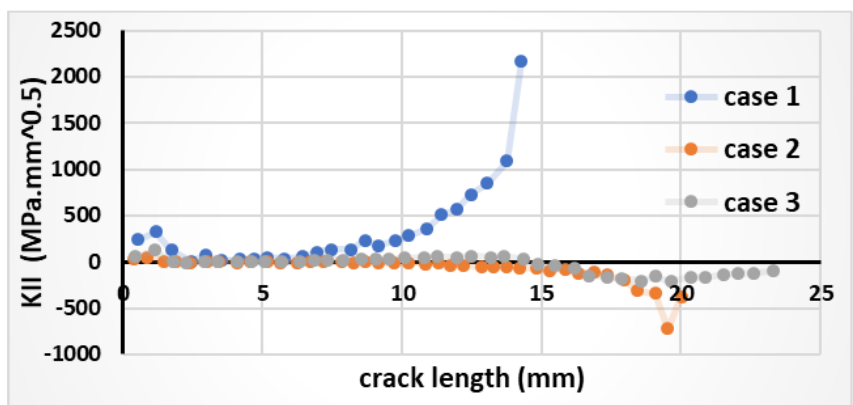

Fig. 9: Mode II stress intensity factor for the three cases

The fatigue life cycle for the three cases are shown in Figure 10. As shown in this figure the number of cycles is also related to the values of stress intensity factors. Higher stress intensity factors leads to increase the fatigue numbers of cycles. In order to show clearly the effect of crack nominal tip position on the stresses distribution as it were affected the stress intensity factors, Figures 11, 12 and 13 show the equivalent Von-Mises stress distribution for the three cases. It can be noticed that the equivalent Von-Mises stress is higher for case 1 compared to the other two cases as which are related strongly to the values of stress intensity factors shown in Figures 9 and 10.

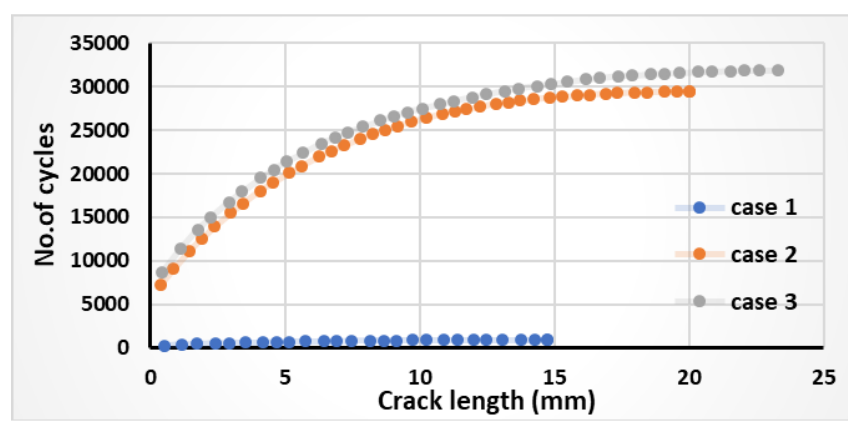

Fig. 10: Fatigue life cycles versus crack length for the three cases
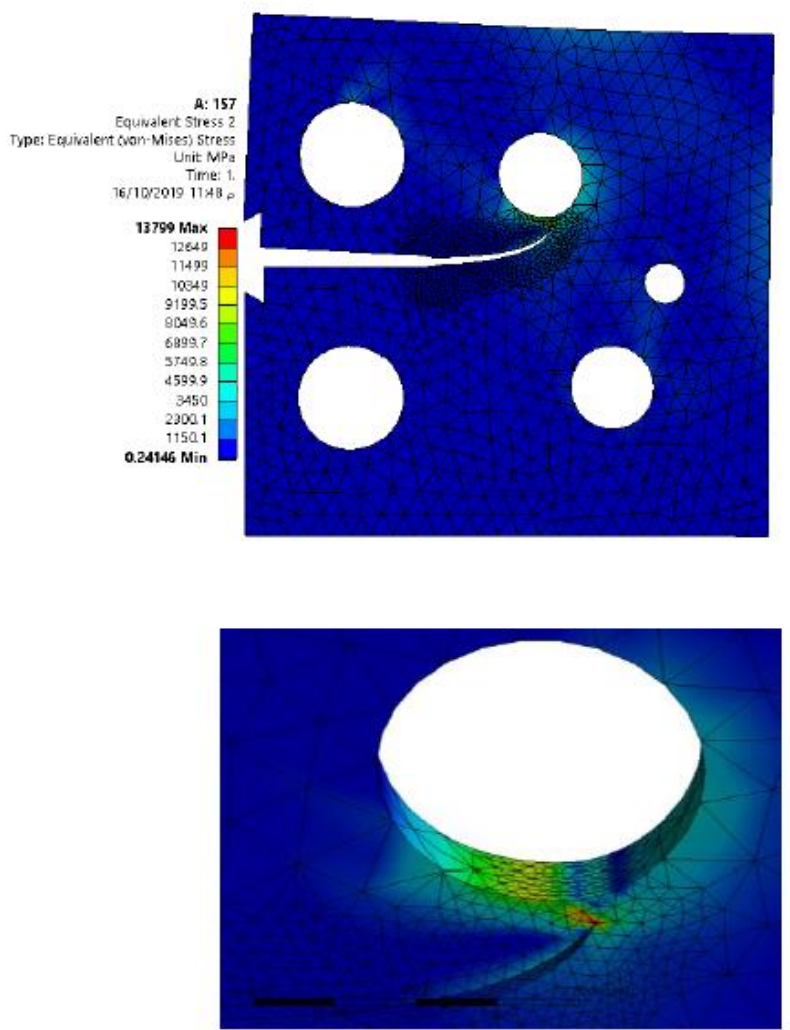

Fig. 11. Equivalent Von-Mises stress distribution for case 1

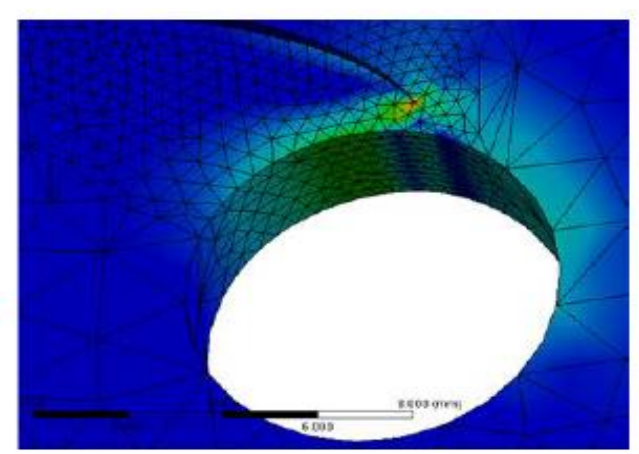

Fig. 12. Equivalent Von-Mises stress distribution for case 2 


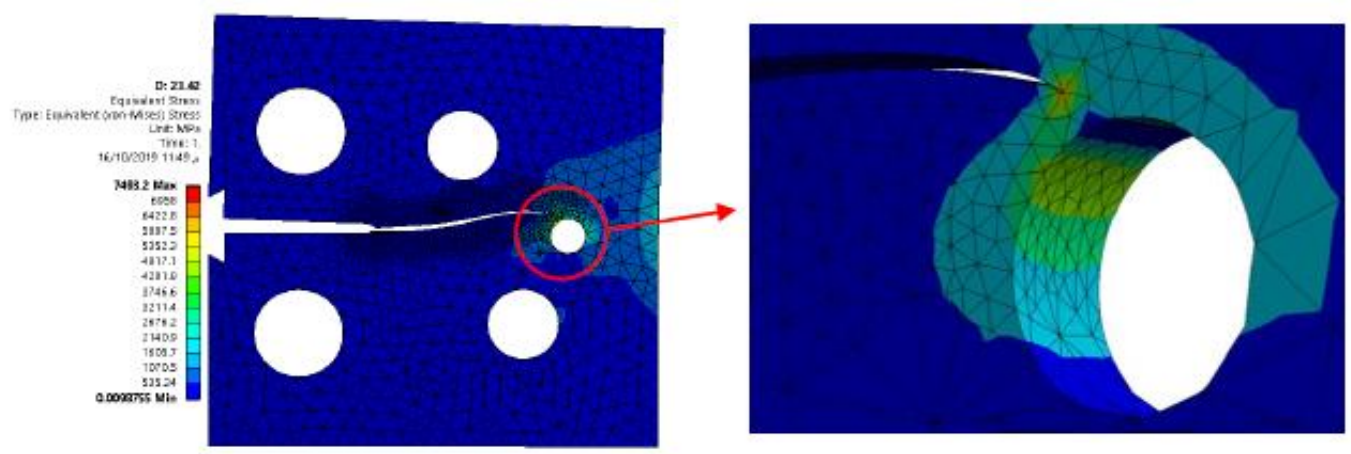

Fig. 13. Equivalent Von-Mises stress distribution for case 3

\section{CONCLUSION}

Three-dimensional simulations of the crack growth in modified compact tension specimens with five holes and different nominal notch tip positions have been performed using Ansys Benchmark software. The presence of the hole in the plate affects the crack to change its direction towards the hole based on the nominal notch tip position and the hole and position. These different of the nominal notch tip positions are also affects the values of stress intensity factors as well as the fatigue life cycles. Validation of the simulation results of the crack path was performed with experimental results with good agreements.

\section{REFERENCES}

1. Anderson, T.L., Fracture mechanics: fundamentals and applications. 2017: CRC press.

2. Tada, P., Paris, and GR Irwin. The Stress Analysis of Cracks Handbook, 2001: p. 2.25.

3. $\quad$ Al Laham, S. and S.I. Branch, Stress intensity factor and limit load handbook. Vol. 3. 1998: British Energy Generation Limited.

4. Infante, V. and J. Silva, Case studies of computational simulations of fatigue crack propagation using finite elements analysis tools. Engineering Failure Analysis, 2011. 18(2): p. 616-624.

5. Mobasher, M.E. and H. Waisman, Adaptive modeling of damage growth using a coupled FEM/BEM approach. International Journal for Numerical Methods in Engineering, 2016. 105(8): p. 599-619.

6. Ren, D.L., S. Wan, and Z.P. Zhong. K Value Calculation of Central Crack Plane Using FRANC2D. 2012. Trans Tech Publ.

7. Alshoaibi, A.M., A Two Dimensional Simulation of Crack Propagation using Adaptive Finite Element Analysis. Journal of Computational Applied Mechanics, 2018. 49(2): p. 335.

8. Alshoaibi, A.M., Finite element procedures for the numerical simulation of fatigue crack propagation under mixed mode loading. Structural Engineering and Mechanics, 2010. 35(3): p. 283-299.

9. Alshoaibi, A.M., M. Hadi, and A. Ariffin, Finite element simulation of fatigue life estimation and crack path prediction of two-dimensional structures components. HKIE Transactions, 2008. 15(1): p. 1-6.

10. Alshoaibi, A.M. and A. Ariffin, Finite element modeling of fatigue crack propagation using a self adaptive mesh strategy. International Review of Mechanical Engineering (IREME), 2008. 2(4): p. 537-544.

11. Alshoaibi, A.M., An Adaptive Finite Element Framework for Fatigue Crack Propagation under Constant Amplitude Loading. International Journal of Applied Science and Engineering, 2015. 13(3): p. 261-270.

12. Rooke, D.P. and D.J. Cartwright, Compendium of stress intensity factors. Procurement Executive, Ministry of Defence. H. M. S. O. 1976, 330 p(Book). 1976.

13. Sih, G.C., Handbook of stress-intensity factors: Stress-intensity factor solutions and formulas for reference. Bethlehem, Pa., Lehigh University, 1973. 815 p, 1973.

14. Broek, D., The practical use of fracture mechanics. 2012: Springer Science \& Business Media.
15. Yaren, M.F., et al., Three-dimensional mode-I/III fatigue crack propagation: Computational modeling and experiments. International Journal of Fatigue, 2019. 121: p. 124-134.

16. Kotousov, A., et al., Three dimensional finite element mixed fracture mode under anti-plane loading of a crack. Theoretical and Applied Fracture Mechanics, 2012. 62: p. 26-33.

17. Erdogan, F. and G. Sih, On the crack extension in plates under plane loading and transverse shear. Journal of basic engineering, 1963. 85(4): p. 519-525

18. D., W., A finite element-based adaptive energy response function method for curvilinear progressive fracture, in Ph.D. thesis, . 2018, The University of Texas: The University of Texas at San Antonio.

19. Wagner, D., et al., A Finite Element-based Adaptive Energy Response Function Method for 2D Curvilinear Progressive Fracture. International Journal of Fatigue, 2019.

\section{AUTHORS PROFILE}

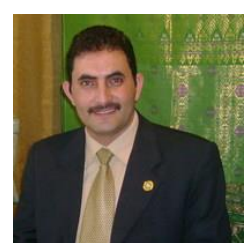

Dr. Abdulnaser M. Alshoaibi: PhD Mechanical and Materials Engineering from National University of Malaysia, Malaysia.

Research work: Experimental and Computational Fracture Mechanics, Finite Element Analysis.

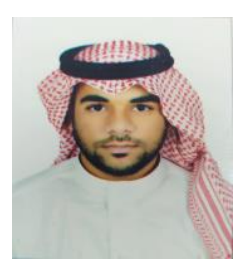

Abdulrahman A. Bin Ghouth : B.SC Mechanical Engineering, Jazan University.

Research work: Experimental and Computational Fracture Mechanics, Finite Element Analysis.

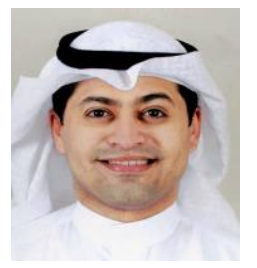

Dr. Yahya Ali Fageehi: PhD Mechanical Engineering, from Akron University, USA.

Research work: Materials testing and destructive testing, Finite Element Analysis, Mechanics of Materials and Structures, Fatigue and fracture behavior of Materials. 